\title{
A preliminary study on gas metal arc welding-based additive manufacturing of metal parts
}

\author{
Van Thao Le*

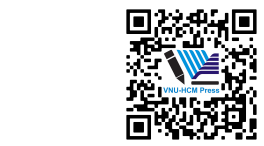 \\ Use your smartphone to scan this \\ QR code and download this article
}

Advanced Technology Centre, Le Quy Don Technical University, 236 Hoang Quoc Viet, Bac Tu Liem, Hanoi, Vietnam

\section{Correspondence}

Van Thao Le, Advanced Technology Centre, Le Quy Don Technical University, 236 Hoang Quoc Viet, Bac Tu Liem, Hanoi, Vietnam

Email: thaomta@gmail.com

History

- Received: 2019-10-03

- Accepted: 2019-11-26

- Published: 2019-02-16

DOI : 10.32508/stdj.v23i1.1714

\section{Check for updates}

\section{Copyright}

(c) VNU-HCM Press. This is an openaccess article distributed under the terms of the Creative Commons Attribution 4.0 International license.

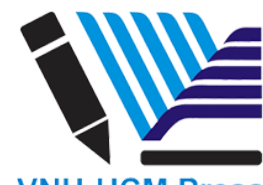

\begin{abstract}
Introduction: In the past three decades, additive manufacturing (AM), also known as 3D printing, has emerged as a promising technology, which allows the manufacture of complex parts by adding material layer upon layer. In comparison, with other metal-based AM technologies, gas metal arc welding-based additive manufacturing (GMAW-based AM) presents a high deposition rate and has the potential for producing medium and large metal components. To validate the technological performance of such a manufacturing process, the internal quality of manufactured parts needs to be analyzed, particularly in the cases of manufacturing the parts working in a critical load-bearing condition. Therefore, this paper aims at investigating the internal quality (i.e., microstructures and mechanical properties) of components manufactured by the GMAW-based AM technology. Method: A gas metal arc welding robot was used to build a thin-walled component made of mild steel on a low-carbon substrate according to the AM principle. Thereafter, the specimens for observing microstructures and mechanical properties were extracted from the built thin-walled component. The microstructures of the specimen were observed by an optical microscope; the hardness was measured by a digital microhardness tester, and the tensile tests were carried out on a tensile test machine. Results: The results show that the GMAW-based AMbuilt thin-walled components possess an adequate microstructure that varies from the top to the bottom of the built component: lamellar structures with primary austenite dendrites in the upper zone; granular structure of ferrites with small regions of pearlites at grain boundaries in the middle zone, and equiaxed grains of ferrites in the lower zone. The hardness (ranged between $164 \pm 3.46$ $\mathrm{HV}$ to $192 \pm 3.81 \mathrm{HV}$ ), yield strength ( $\mathrm{YS}$ of fset of $0.2 \%$ ranged from $340 \pm 2 \mathrm{MPa}$ to $349.67 \pm 1.53 \mathrm{MPa}$ ), and ultimate tensile strength (UTS ranged from $429 \pm 1 \mathrm{MPa}$ to $477 \pm 2 \mathrm{MPa}$ ) of the GMAW-based AM-built components were comparable to those of wrought mild steel. Conclusions: The results obtained in this study demonstrate that the GMAW-based AM-built components possess adequate microstructure and good mechanical properties for real applications. This allows us to confirm the feasibility of using a conventional gas metal arc welding robot for additive manufacturing or repairing/re-manufacturing of metal components.
\end{abstract}

Key words: Additive manufacturing, Gas metal arc-based additive manufacturing, Mild steel, Microstructures, Mechanical properties

\section{INTRODUCTION}

In the past three decades, Additive manufacturing $(\mathrm{AM})$, also known as $3 \mathrm{D}$ printing, has emerged as a promising solution for manufacturing complex geometries and parts made of materials that are expensive and/or difficult to machine, for example, titanium and nickel alloy ${ }^{1}$. In contrast to machining processes, AM technology builds a solid part by adding materials layer-by-layer from a substrate without using any additional resources such as cutting tools, cooling fluid, and fixture system ${ }^{2}$. Nowadays, AM technologies - in particular, metal-based AM, have been efficiently applied in different sectors, for example, aerospace, automotive and biomedical engineering ${ }^{1,3-5}$.

Metal-based AM systems can be categorized based on the material feedstock, energy source, and so on. Ac- cording to the heat source used in AM, metal-based AM technologies can be classified into laser-based, electron beam-based, and arc welding-based additive manufacturing ${ }^{4}$. In comparison with laser-based and electron beam-based AM systems, welding-based additive manufacturing - also called wire arc additive manufacturing (WAAM) has demonstrated as a prospective solution for the manufacture of medium and large-dimensional metal parts ${ }^{6}$. Moreover, WAAM presents a higher deposition rate, lower equipment costs, and low production costs ${ }^{7-9}$. In WAAM systems, an industrial robot or a CNC machine tool is normally used to provide accurate movements of welding torch during the build of components. The arc heat source used in a WAAM system can be gas metal arc welding (GMAW), gas tung- 
sten arc welding (GTAW), and plasma arc welding $(\mathrm{PAW})^{6,8}$. In terms of productivity, the deposition rate of GMAW-based AM is two or three times higher than that of GTAW- and PAW-based $\mathrm{AM}^{10}$. That is why GMAW-based AM is more suitable than GTAWand PAW-based AM for the manufacture of metal par ts with large dimensions.

In the literature, much research has been carried out on WAAM. Most of the published works focused on observing the influence of process parameters on the geometry of built components ${ }^{8,11-13}$. For example, Xiong et al. ${ }^{8}$ investigated the influences of main process parameters (e.g., wire feed speed, travel speed, and inter-layer temperature) on surface roughness of thin-walled parts built by GMAW-based AM. In their work, a better understanding of the influential mechanisms of the process parameters on the surface roughness was presented. The authors showed that the surface quality of thin-walled components could be improved by decreasing the inter-layer temperature. The increase of the wire feed speed was associated with the increase of the surface roughness, and so on.

On the other hand, not much research on the internal quality of WAAM-built parts has been carried out. Suryakumar et al. ${ }^{14}$ investigated the effects of heating cycles on the tensile properties and the hardness of low-carbon steel produced by the GMAWbased AM process. The authors highlighted that thermal cycles have negligible effects on material properties after around five deposited layers. Chen et al. ${ }^{15}$ studied microstructures and mechanical properties of stainless steel $316 \mathrm{~L}$ components manufactured by the GMAW-based AM process. They found that the tensile properties of GMAW-based AM-built $316 \mathrm{~L}$ steel were comparable to those of wrought $316 \mathrm{~L}$.

In fact, the internal quality of parts is a very important criterion, which allows us to demonstrate the technical performance of the manufacturing process. Thus, a better understanding of microstructures and mechanical properties of components manufactured by GMAW-based AM is necessary for the production decision, especially for components that work in a critical load-bearing condition. In addition, studies related to AM technologies in Vietnam are very limited. Most of the 3D printers available in Vietnam are only capable of printing plastic and non-metallic materials. The main reason is that the investment costs for a metal-based AM system are still very expensive. To overcome this difficulty, the selection of an arc welding system, which is readily available and has low costs of investment for the research on metal-based AM, is consistent in Vietnam.
Therefore, the objective of this study is to investigate the internal quality of thin-walled parts manufactured by the GMAW-based AM process. The results obtained in this study allow us to demonstrate the feasibility of using the GMAW robot for manufacturing or repairing/remanufacturing of metal components according to the AM principle.

This paper is organized as follows: Section MATERIALS AND METHODS describes the materials and experimental methods. In Section RESULTS, the main results on microstructures and mechanical properties of built materials are presented. Section DISCUSSION is intended for conclusions and future work.

\section{MATERIALS - METHODS}

\section{Materials}

In this study, the mild steel copper-coated welding wire (ER70S-6, supplied by Changzhou City Yunhe Welding Material Company of China) with a diameter of $1.2 \mathrm{~mm}$, and a low-carbon steel plate (SS400, manufactured by Jaway Metal Company of China) with dimensions of $250 \mathrm{~mm}$ in length, $100 \mathrm{~mm}$ in width, and $10 \mathrm{~mm}$ in thickness were used to build a thin-walled sample. Before depositing the first welding layer, the substrate surface was machined to remove oxide scale and rust. The chemical compositions of the welding wire and the substrate are shown in Table 1.

The thin-walled sample was built according to the WAAM process by an industrial GMAW robot (Panasonic TA-1400, provided by Panasonic Welding System Company of Japan) (Figure 1a). In this system, the 6-axis robot (1) implements the movement of the welding torch (5) to deposit successive welding layers from the substrate. The welding process was controlled by the welding power source (2).

\section{Building the thin-walled sample}

The welding process parameters used to build the thin-walled sample are shown in Table 2. These parameters were chosen based on the recommendations of the manufacturer of welding wires and material properties.

The distance between the GMAW torch and the workpiece was $12 \mathrm{~mm}$. The deposition was conducted at room temperature and without preheating the substrate. Once the deposition of a welding layer was finished, the welding torch is retracted to the beginning point for the deposition of the next layer with a dwell time of 60 seconds. The dwell time used between two successive layers aims at cooling down the workpiece and transferring accumulated heat to the environment. The final cooling of the built thin wall 
Table 1: Chemical compositions of wire and substrate materials (in wt. \%) ${ }^{16}$

\begin{tabular}{lccccccccc}
\hline Element & $\mathrm{C}$ & $\mathrm{Si}$ & $\mathrm{Mn}$ & $\mathrm{P}$ & $\mathrm{S}$ & $\mathrm{Al}$ & $\mathrm{Ca}$ & $\mathrm{Cu}$ & $\mathrm{Fe}$ \\
Wire (ER70S-6) & 0.04 & 0.92 & 0.45 & 0.011 & 0.015 & - & - & 0.2 & Balance \\
Substrate (SS400) & 0.05 & 0.037 & 0.46 & 0.013 & 0.002 & 0.044 & 0.0017 & - & Balance \\
\hline
\end{tabular}

was carried in the calm air of the room. During the building process, a gas of $100 \% \mathrm{CO} 2$ with a constant flow rate of $20(\mathrm{~L} / \mathrm{min})$ was used for the shielding. The built thin- walled sample was presented in Figure $1 \mathrm{~b}$ and c. Its dimensions are approximately $140 \mathrm{~mm}$ in length, $80 \mathrm{~mm}$ in height, and $4.5 \mathrm{~mm}$ in thickness.

\section{Microstructures observation and hardness measurement}

To observe microstructures and measure the hardness of the built material, a specimen (MS, Figure 1c and d) was cut from the built thin-walled sample by using a wire-cut Electrical Discharge Machining (EDM) machine (Aristech CW-10, supplied by Lien Sheng Mechanical \& Electrical Company of Taiwan). Subsequently, the EDM-cut surface of this specimen was grinded and chemically etched. The microstructure of the specimen was observed using an optical microscope AXIO A2M of Carl Zeiss Company. The hardness was measured by a digital microhardness tester (Vicker FV-310 of Future-Tech Company) with a load of $5 \mathrm{kgf}(49.05 \mathrm{~N})$.

\section{Tensile tests}

For observing tensile properties of built materials, two groups of tensile specimens in the vertical (TSv1, TSv2, TSv3) and horizontal (TSh1, TSh2, TSh2) direction s were cut from the built thin-walled sample by using the wire-cu $\mathrm{EDM}$ machine (Figure 1c). Before cutting these specimens, two side surfaces of the built thin wall were machined to obtain an effective width of the built thin-walled materials. The dimensions of the tensile specimens are shown in Figure 2.

Unit: $\mathrm{mm}$; thickness: $2 \mathrm{~mm}$

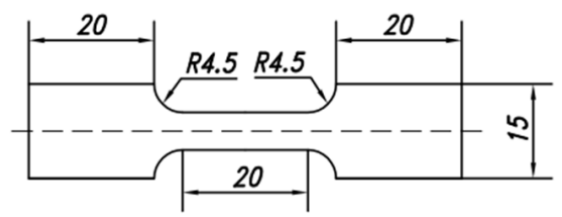

Figure 2: Dimensions of the tensile specimen.

Their cross-section and length for examining tensile properties are $6 \mathrm{~mm} \times 2 \mathrm{~mm}$ and $20 \mathrm{~mm}$, respectively.
The tensile tests were conducted on the tensile test machine (INSTRON 3369 of Instron Company) with a crosshead displacement speed of $1.2 \mathrm{~mm} / \mathrm{min}$ and at room temperature.

\section{RESULTS}

\section{Microstructures}

Figure 3 presents the microstructure of the specimen MS observed in five zones: the upper zone, the middle zone, the lower zone, the heat-affected zone (HAZ), and the substrate zone (as illustrated in Figure 1d).

The upper zone (Figure 3a) presents lamellar structures with primary austenite dendrites that distribute along the cooling direction - perpendicular to the substrate. In addition, the upper zone has a sudden high variation of thermal and a high-cooling rate because it contacts calm air at room temperature, thus resulting in three types of ferrite grains: allotriomorphic ferrite $\alpha$, Widmanstatten ferrite $\alpha_{w}$, and acicular ferrite $\alpha_{a}$. The middle zone is mainly characterized by the granular structure of ferrites with small regions of pearlites at grain boundaries (Figure 3b). In this zone, it was also found that there are two types of grains: granular grains in the overlapped zone with a relatively large size and equiaxed grains with a dense distribution in the non-overlapped zone. The reason is that the heat of molten pool, which forms the current deposited layer (e.g., layer $i+1$ ), reheats and re-melts the previously built layer (e.g., layer $i$ ), resulting in the solidstate phase transformation in the overlapped zone, for example, grain growth, recrystallization, and phase transitions.

On the other hand, the microstructures in the lower zone consist of equiaxed grains of ferrite, in which thin lamellae are distributed and coexisting with thin strips of pearlite (Figure 3c). The lower zone undergoes a slow er cooling rate when compared to the upper zone, resulting in ferrite phases. It is also observed that the grain size in the lower zone is finer than that in the middle zone. The reason is that the value of the thermal shock of the lower zone is higher with respect to the middle zone. The lower zone (including about 4 first deposited layers) contacts the cold substrate, while the middle zone contacts the warm deposited layer ${ }^{18}$. In addition, the middle zone presents a thermal gradient lower than that of the lower zone ${ }^{19}$. 


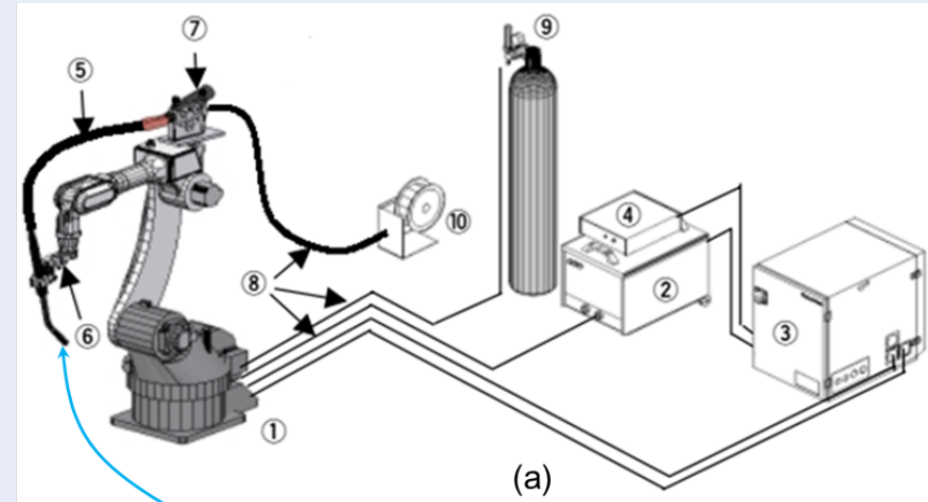

(1) Robot

(2) Welding power source

(3) Robot controller

(4) Encoder conversion unit

(5) Welding torch

6) Safety torch holder

(7) Wire feeder

(8) Cable unit

(9) Gas regulator

(10) Wire reel stand

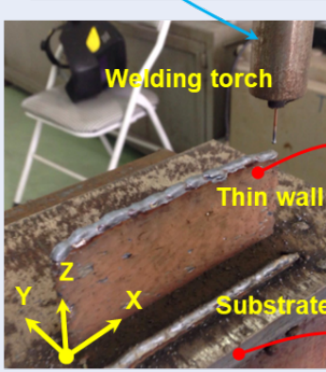

(b)

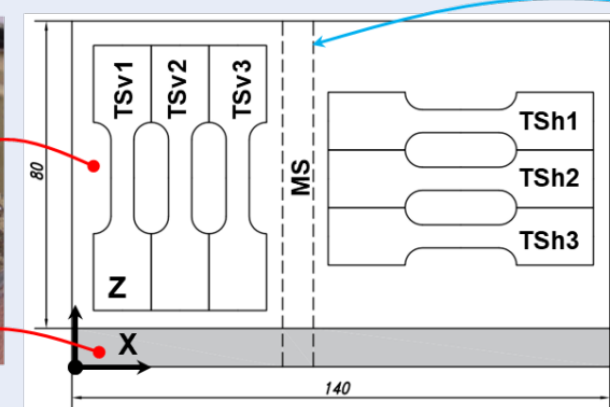

(c)

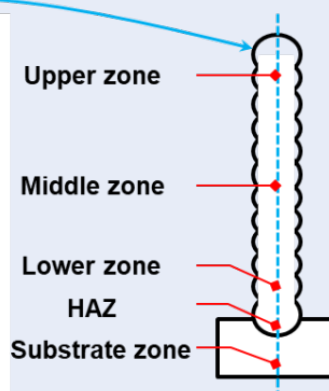

(d)

Figure 1: (a) Schema of the GMAW-based AM system ${ }^{17}$, (b) the built thin-walled sample, (c) the positions for cutting the specimens and (d) five zone $s$ for observing microstructures and measuring the hardness on a cut surface of the specimen.

Table 2: Process parameters used to build the thin-walled sample

\begin{tabular}{ccccc}
\hline $\begin{array}{c}\text { Process } \\
\text { parameters }\end{array}$ & $\begin{array}{c}\text { Travel speed } \\
(\mathrm{mm} / \mathrm{min})\end{array}$ & $\begin{array}{c}\text { Welding current } \\
\text { Value }\end{array}$ & $\begin{array}{c}\text { Welding Voltage } \\
(\mathrm{V})\end{array}$ & $\begin{array}{c}\text { The flow rate of shielding gas } \\
(\mathrm{L} / \mathrm{min})\end{array}$ \\
\hline
\end{tabular}

Figure $3 \mathrm{~d}$ presents microstructures of the heataffected zone (HAZ). It can be found that there is a microstructure transformation from austenite to martensite. The substrate zone presents a typical ferrite/perlite banded microstructures of the low-carbon steel obtained by the hot rolling process (Figure 3e). This type of microstructure is opposite to the homogenous distribution of phases observed in the middle zone.

\section{Hardness}

Table 3 shows the results of hardness measurement in five zones of microstructure observation. For each zone, the hardness (HV) was measured at five positions that distribute on the "centerline" of the crosssection from the top to the bottom of the specimen MS (Figure 1d). It is also noted that the reported hardness test results for each measured position in Ta- ble 3 are the average value of three different indentation points on polished surfaces of the specimen MS. In the thin-walled part, the upper zone presents the highest hardness value, and the middle zone has the lowest hardness value. The average hardness value of $192 \pm 3.81 \mathrm{HV}, 163.8 \pm 5.63 \mathrm{HV}$, and $175.8 \pm 2.77$ $\mathrm{HV}$ was obtained in the upper zone, the middle zone, and the lower zone, respectively. The HAZ present a hardness value slightly lower than that of the substrate zone $(222.6 \pm 2.70 \mathrm{HV}$ versus. $224 \pm 3.52 \mathrm{HV}$, Table 3).

\section{Tensile properties}

Figure 4 shows the installation of a specimen on the tensile machine (Figure 4a), two examples of the broken specimens after the tensile tests (Figure $4 \mathrm{~b}$ ), and typical engineering strain-stress curves (Figure 4c) 

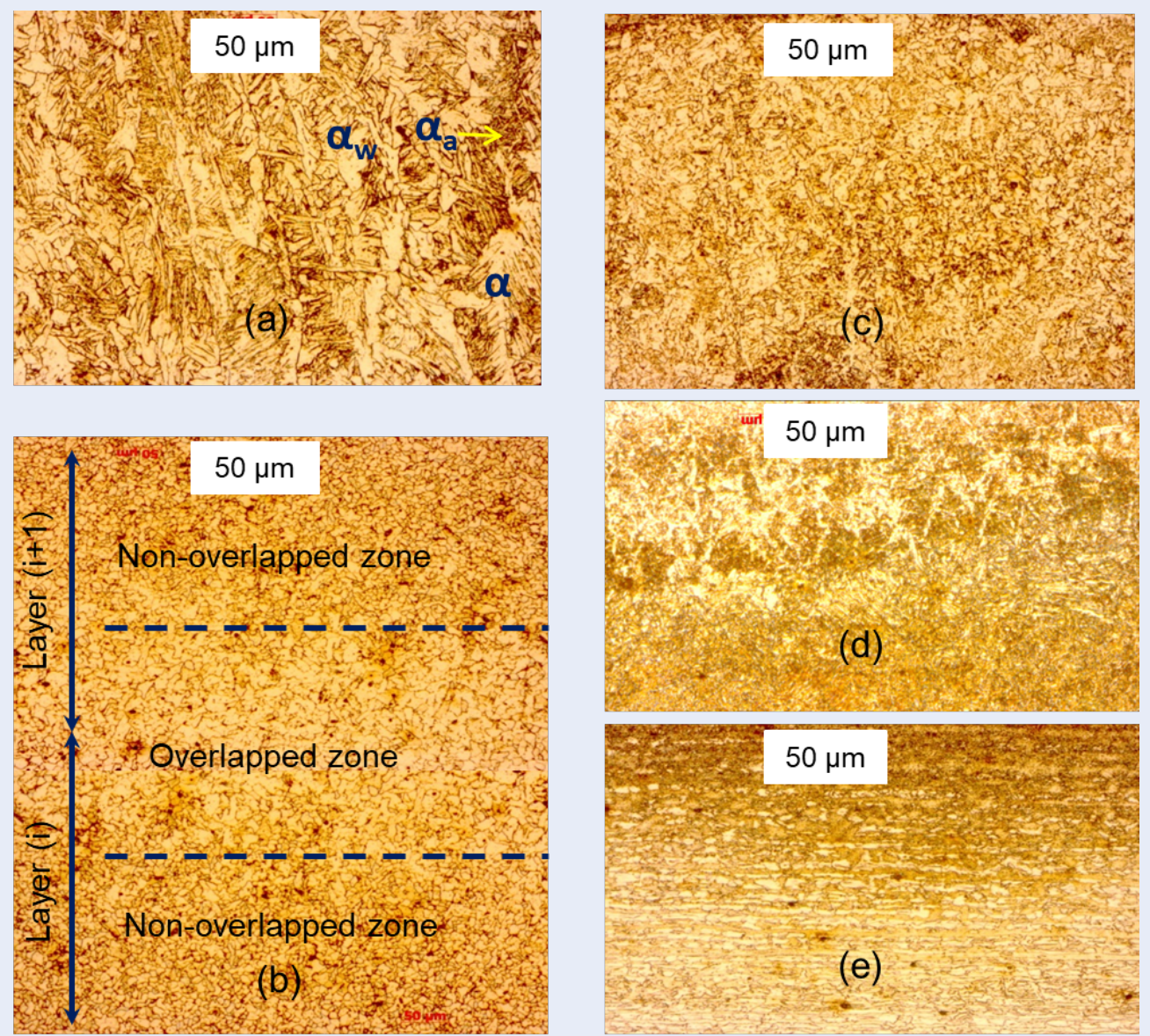

Figure 3: Microstructure s of built materials observed in five zones. (a) the upper zone, (b) the middle zone, (c) the lower zone, (d) the heat- affected zone, and (e) the substrate zone.

Table 3: Measurement of hardness (HV) in different zones of the specimen MS

\begin{tabular}{ccccccc}
\hline \multicolumn{2}{c}{ Measured zone } & Upper zone & Middle zone & Lower zone & HAZ & $\begin{array}{c}\text { Substrate } \\
\text { zone }\end{array}$ \\
& & & & & & 225 \\
& Position 1 & 197 & 167 & 171 & 221 & 225 \\
& Position 2 & 192 & 162 & 178 & 219 & 223 \\
Hardness value (HV) & Position 3 & 187 & 159 & 177 & 223 & 226 \\
& Position 4 & 190 & 165 & 176 & 224 & 222 \\
& Position 5 & 194 & 167 & 177 & 226 & $224 \pm 1.58$ \\
\hline
\end{tabular}


obtained from the tensile tests of two tensile specimens in the vertical and horizontal directions (TSv1 and TSh1 specimens). The yield strength (YS, offset of $0.2 \%$ ) and ultimate tensile strength (UTS) of all tensile specimens are given in Table 4.

Table 4: YS and UTS values of vertical and horizontal specimens

\begin{tabular}{ccc}
\hline Tensile properties & $\begin{array}{c}\text { YS (offset of } \\
0.2 \%, \mathrm{MPa})\end{array}$ & $\begin{array}{c}\text { UTS } \\
(\mathrm{MPa})\end{array}$ \\
TSv1 & 348 & 477 \\
TSv2 & 351 & 479 \\
TSv3 & 350 & 475 \\
Average value of vertical & $349.67 \pm 1.53$ & $477 \pm$ \\
specimens & & 2 \\
TSh1 & 338 & 428 \\
TSh2 & 342 & 430 \\
TSh3 & 340 & 429 \\
Average value of & $340 \pm 2$ & $429 \pm$ \\
horizontal specimens & & 1 \\
ASTM A36 steel ${ }^{20}$ & 250 & $400-$ \\
& & 550 \\
\hline
\end{tabular}

\section{DISCUSSION}

The microstructures of GMAW-based AM-built thinwalled component vary from the top to the bottom of the built sample with different structures, i.e., lamellar structures with primary austenite dendrites in the upper zone; granular structure of ferrites with small regions of pearlites at grain boundaries in the middle zone, and equiaxed grains of ferrite in the lower zone. This microstructure formation is due to the reheating and remelting effect induced by successive layer depositions and different cooling conditions in each zone. The microstructural characteristics of the built thinwalled component observed in this study are similar to those reported in the previous studies ${ }^{18,20,21}$. The microstructures of the built thin-walled parts could also be adjusted by using alternating cycles of cooling or rolling deposited layers ${ }^{6}$. Moreover, the built sample also presents a continued transition of microstructures in the interface zone between the welded materials and the substrate. This demonstrates a strong metallurgical bonding between the built materials and the substrate.

Due to the variation of microstructures of built materials from the upper to the lower zones, as observed in subsection 3.1, the hardness of built materials also changes in a consistent way. Due to the presence of the Widmanstatten structure in the upper zone (Figure 4a), the hardness of the upper zone is higher than that of the middle and lower zones (192 \pm 3.81 $\mathrm{HV}$ in comparison with $163.8 \pm 5.63 \mathrm{HV}$ and $175.8 \pm$ 2.77 HV, Table 3). Similarly, the lower zone characterized by lamellae structures results in higher hardness values than those in the middle zone. The HAZ hardness value is lower than that of the substrate zone because the metal in the upper HAZ was heated and partially melted by the heat of molten materials of the first layers, resulting in softening effects. Lastly, it is found that the hardness of the built materials is comparable to that of wrought ASTM A36 steel (about 168 $\mathrm{HV}$ ), which $\mathrm{h}$ as a similar chemical composition with ER70S-6 steel.

From Figure 4, it is first found that the strain-stress curves of all specimens present an elastic region at the onset of load applications and followed by inhomogeneous yielding at the elastic and plastic transition. This shows a typical behavior for mild steels ${ }^{22}$. Secondly, the average values of YS and UTS are statistically different between the vertical and horizontal specimens (with $\mathrm{p}$-value $=0.001$ for $\mathrm{YS}$ and $\mathrm{p}$-value $\approx 0$ for UTS). The vertical specimens reveal higher values of UTS when compared to the UTS values of the horizontal specimens. As shown in Table 4, the UTS values of the vertical specimens ranged from 475 $\mathrm{MPa}$ to $479 \mathrm{MPa}$ with an average value of $477 \mathrm{MPa}$ and standard deviation of \pm 2 , whereas the UTS values obtained for the horizontal specimens ranged from 428 $\mathrm{MPa}$ to $430 \mathrm{MPa}$ with an average value of $429 \mathrm{MPa}$ and standard deviation of \pm 1 . Similarly, the YS values obtained from the vertical specimens are also higher than those of the horizontal specimens, $349.67 \pm 1.53$ $\mathrm{MPa}$ in comparison with $340 \pm 2 \mathrm{MPa}$ (Table 4). This significant difference in terms of YS and UTS values between the vertical and horizontal specimens may be due to non-uniform microstructures of built materials. Moreover, the YS values of these specimens are higher than that of wrought A36 steel (about 250 $\mathrm{MPa}$ ). On the other hand, the UTS values of these specimens are in the value range of wrought ASTM A36 steel $(400-550 \mathrm{MPa})^{20}$. These results demonstrate the good mechanical properties of the GMAW-based AM-built components.

\section{CONCLUSIONS}

This paper presents a preliminary study in our project on the use of an industrial GMAW robot for additive manufacturing or remanufacturing of metal parts. In this work, a thin-walled sample made of mild steel 




(a)

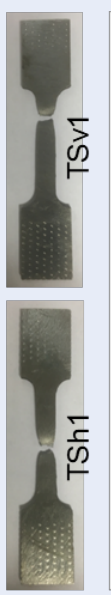

(b)

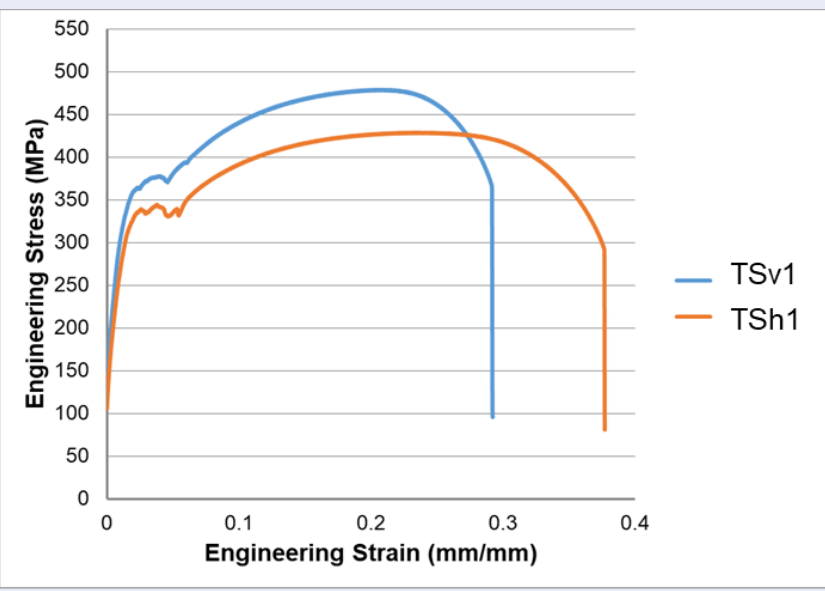

(c)

Figure 4: Tensile tests with two specimens TSv1 and TSh1: (a) Installation of the specimen on the tensile test machine, (b) the broken specimens after the tensile tests, and (d) the engineering stress-strain curves.

was built to investigate microstructures and mechanical properties. The results show that the microstructure of built materials varies from the top to the bottom of built samples in four zones: the upper zone, the middle zone, the lower zone, and the heat-affected zone of substrate materials. The upper zone of built materials presents the highest hardness value (192 $\pm 3.81 \mathrm{HV}$ versus $163.8 \pm 5.63 \mathrm{HV}$ in the middle zone and $175.8 \pm 2.77 \mathrm{HV}$ in the lower zone). There is also a significant difference in terms of YS and UTS between the vertical and horizontal specimens due to non-uniform microstructures of built materials. Moreover, the mechanical properties of the thinwalled component built by the GMAW-based AM process are comparable with those of parts manufactured by traditional processes such as forging and machining. Hence, the components built by the GMAWbased AM process are adequate for industrial applications. This confirms the feasibility of using the GMAW robot for additive manufacturing of parts or repairing/remanufacturing of damaged components. In future works, we will focus on optimizing process parameters and evaluating the economic efficiency and environmental performance of the GMAW-based AM process.

\section{LIST OF ABBREVIATIONS}

AM: Additive Manufacturing EDM: Electrical Discharge Machining

GMAW: Gas Metal Arc Welding GTAW: Gas Tungsten Arc Welding HAZ: Heat Affected Zone
PAW: Plasma Arc Welding

UTS: Ultimate Tensile Strength

WAAM: Wire Arc Additive Manufacturing

YS: Yield Strength

\section{COMPETING INTERESTS}

The author declares that this paper has no competing interests.

\section{ACKNOWLEDGMENT}

This research is funded by the Vietnam National Foundation for Science and Technology Development (NAFOSTED) under grant number 107.99-2019.18.

\section{REFERENCES}

1. Guo N, Leu M. Additive manufacturing: technology, applications and research needs. Front Mech Eng. 2013;8:215-243.

2. Herzog D, Seyda V, Wycisk E, Emmelmann C. Additive manufacturing of metals. Acta Mater. 2016;117:371-392.

3. Gardan J. Additive manufacturing technologies: state of the art and trends. Int J Prod Res. 2015;7543:1-15.

4. Frazier WE. Metal Additive Manufacturing: A Review. J Mater Eng Perform. 2014;23:1917-1928.

5. Vayre B, Vignat F, Villeneuve F. Metallic additive manufacturing: state-of-the-art review and prospects. Mech Ind. 2012;13:89-96.

6. Williams SW, et al. Wire + Arc Additive Manufacturing. Mater Sci Technol. 2016;32:641-647.

7. Ding $D$, et al. Towards an automated robotic arc-weldingbased additive manufacturing system from CAD to finished part. CAD Comput Aided Des. 2016;73:66-75.

8. Xiong J, Li Y, Li R, Yin Z. Influences of process parameters on surface roughness of multi-layer single-pass thin-walled parts in GMAW-based additive manufacturing. J Mater Process Technol. 2018;252:128-136.

9. Yang $D, H e C$, Zhang G. Forming characteristics of thin-wall steel parts by double electrode GMAW based additive manufacturing. J Mater Process Technol. 2016;227:153-160. 
10. Wu B, et al. A review of the wire arc additive manufacturing of metals: properties, defects and quality improvement. J Manuf Process. 2018;35:127-139.

11. Dinovitzer $M$, Chen $X$, Laliberte J, Huang $X$, Frei $H$. Effect of wire and arc additive manufacturing (WAAM) process parameters on bead geometry and microstructure. Addit Manuf. 2019;26:138-146.

12. Zhang Z, Sun C, Xu X, Liu L. Surface quality and forming characteristics of thin-wall aluminium alloy parts manufactured by laser assisted MIG arc additive manufacturing. Int J Light Mater Manuf. 2018;1:89-95.

13. Youheng F, Guilan W, Haiou Z, Liye L. Optimization of surface appearance for wire and arc additive manufacturing of Bainite steel. Int J Adv Manuf Technol. 2017;91:301-313.

14. Suryakumar S, Karunakaran K, Chandrasekhar U, Somashekara M. A study of the mechanical properties of objects built through weld-deposition. Proc Inst Mech Eng Part B J Eng Manuf. 2013;227:1138-1147.

15. Chen $X$, et al. Microstructure and mechanical properties of the austenitic stainless steel $316 \mathrm{~L}$ fabricated by gas metal arc additive manufacturing. Mater Sci Eng A. 2017;703:567-577.

16. Pham TH, Kim JJ, Kim SE. Estimation of microstructural compositions in the weld zone of structural steel using nanoinden- tation. J Constr Steel Res. 2014;99:121-128.

17. AllAlloy. TA G2 Series Welding Robot. Available from: http: //www.allalloy.com/.

18. Liberini M, et al. Selection of Optimal Process Parameters for Wire Arc Additive Manufacturing. Procedia CIRP. 2017;62:470474.

19. Yang $D$, Wang $G$, Zhang $G$. Thermal analysis for single-pass multi-layer GMAW based additive manufacturing using in frared thermography. J Mater Process Technol. 2017;244:215224.

20. Haden CV, et al. Wire and arc additive manufactured steel: Tensile and wear properties. Addit Manuf. 2017;16:115-123.

21. Rafieazad M, Ghaffari $M$, Nemani AV, Nasiri A. Microstructural evolution and mechanical properties of a low-carbon lowalloy steel produced by wire arc additive manufacturing. Int J Adv Manuf Technol. 2019;Available from: 10.1007/s00170019-04393-8.

22. Yan JB, Liew JYR, Zhang MH, Wang JY. Mechanical properties of normal strength mild steel and high strength steel S690 in low temperature relevant to Arctic environment. Mater Des. 2014;61:150-159. 